\title{
20 世纪以来美国土地用途管制发展历程的回顾与展望
}

\author{
Land Use Control Trends in the United States Since the 20th Century
}

马丁·贾菲 著 于洋 译

Written by Martin Jaffe, Translated by Yu Yang

\begin{abstract}
摘要: 本文主要回顾了美国土地用途管制的 发展历程, 从 20 世纪上半叶的区划 (法), 经 由二战后的理性规划和 1970 年代的历史保护 和美学管制, 发展到 1990 年代的新都市主义 和形态条例。进入 21 世纪后, 随着生态环境 保护日益成为主流, 美国土地用途管制正逐渐 向 19 世纪去中心化的传统回归。

Abstract: This paper makes a historical review of land use control in the USA. It has experienced the development from zoning in the first half of the 20th Century, through rational planning after WWII and later historic preservation and aesthetic regulation, to new urbanism and formbased code in the 1990s. In the 21st Century, land use control in the USA pays more attention to the environmental protection and is embracing the regulatory philosophies of decentralization in the 19th Century.
\end{abstract}

关键词: 美国土地用途管制; 发展历程; 区划（法）；理性规划；形态条例； 环境保护

Keywords: Land Use Control in the USA; Historical Review; Zoning; Rational Planning; Form-based Code; Environmental Protection

作者: 马丁 · 贾菲, 美国伊利诺伊大学芝加哥分 校荣休副教授。mjaffe@uic.edu

译者: 于洋, 中国人民大学公共管理学院城市 规划与管理系, 助理教授, 硕士生导师。 yuyang319@ruc.edu.cn
美国的土地利用植根于土地的私有和私用制度。自建国以来, 美国在土地管 理上继承了英国的普通法传统, 国家法律赋予私人依据合同法和妨害法原则进行 诉讼的权利。这使得私人土地所有者或业主委员会有权在土地使用和买卖的合约 中设置限制性条款, 并强制执行, 以此对后续土地所有者的不动产使用和转让起 到限制作用。在妨害法框架下, 当土地所有者认为邻人的行为对其所有的土地使 用或收益产生过度妨害时, 即可以对邻人提起诉讼。在过去的 100 年中, 通过司 法判决、公平住房法和民权法已对具有法律强制力的民间契约限制性条款产生了 一定的限制。例如，在美国宪法公平保护条款下，为了推进联邦反歧视的政策， 民间契约中因种族或宗教的原因反对将私人不动产卖给特定人群的限制性条款已 不再享有法律上的强制力。尽管如此, 关于妨害行为的私法、民间契约和限制性 条款在当今美国依然是规制土地开发的有效工具, 100 年前很多被认为构成公共 或私人妨害的不当私人行为在现行的土地用途管制中已被明令禁止。

在 20 世纪的大部分时间里，除了授予私人基于保护个人财产权利的诉权外, 联邦和州宪法、州和城市法规以及各级政府的土地利用规划和发展政策共同推进 了对私人不动产的使用权和所有权的保护。美国宪法修正案中规定, 私人财产必 须在满足公共用途且得到公平补偿的前提下才能被政府征用；任何人的财产未经 正当程序不得被剥夺。州和城市则通过法规（例如《州区划授权法案》）授权编 制和强制推行土地用途管制。本文将追溯在宪法和法律设定的框架下美国各州和 地方土地利用规划和土地用途管制的演变轨迹, 对 20 世纪和 21 世纪初涉及美国 土地规划政策和程序的管制趋势和发展问题进行考察, 并在文章结尾试图对未来 几十年土地利用规划与管制的发展趋势进行预测。

\section{1900-1950 年间的土地用途管制}

20 世纪上半叶的土地用途管制主要以两股潮流为代表 : 一是联邦最高法院对 于俄亥俄州欧几里得村区划诉讼案件做出了合宪的司法判决; 二是 1920 年代由联 邦商务部颁布的《标准区划授权法案》(Standard Zoning Enabling Act), 专门将欧 几里得区划条例作为样板向全国推行。在 1920 年代之前, 美国少数大城市 (例如 纽约市）为了解决因为土地高强度开发带来的公共卫生问题（保证充足光照和通 风以及保持防火通道畅通等), 已经开始推行开发管制, 主要针对建筑高度和退让 距离做出了规定 ${ }^{[1]}$ 。但是与这些仅针对建筑体量的早期管制不同, 欧几里得村通 
过地方法规的形式首次对土地用途、建筑高度、开发密度等 进行了规制, 将土地分为居住、商业和工业用地, 每类用地 只能按照法规的要求进行开发。这种做法在很大程度上影响 了私有土地开发和转让的价值, 对私人财产权构成了限制。

美国最高法院在 1926 年欧几里得村诉安博乐不动产公司 案 (Village of Euclid v. Ambler Realty Co.) 中做出了欧几里得 村区划合宪的判决。此后在经历了 1930 年代大萧条和 1940 年代全球性冲突之后, 随着城市开发重新启程, “欧几里得式” 区划在美国被广泛采用。联邦政府的《标准区划授权法案》 被各州广泛参考, 促进了区划实践的标准化和统一性。尽管 各州关于城市区划条例的适用范围和权威性的司法原则有些 许差异, 并且州立法机关也根据具体情况对《标准区划授权 法案》做了小幅调整，但是各州区划授权法案和地方条例在 适用范围、结构和管理上仍在很大程度上保留了联邦标准中 的统一性。在《标准区划授权法案》颁布 90 年后的今天，这 种统一性在大多数城市区划条例中依然有所体现。例如, 从 区划条例的角度来看, 怀俄明州的一个郊区城市与弗吉尼亚 州或者堪萨斯州的另一个郊区城市也许没什么不同。

欧几里得式区划在美国成为主导的土地用途管制工具。 无论是历史上的还是当代的经典欧几里得式区划主要解决 了土地开发中的四类问题。首先，它管制了土地和建筑的用 途。主要的做法是将社区划分为居住、商业、工业和政府分 区, 并对每类分区土地列出首要土地用途、附属土地用途和 通过羁束审批的有条件土地用途。其次, 它管制了土地开发 强度。主要做法是对每类分区土地的最小用地面积、用地形 状、面向街道的最小面宽等进行规定。再次, 它管制了建筑 体量。主要做法是对位于不同用途土地上的建筑高度和容积 率进行限制。最后, 它管制了建筑的位置。主要做法是对建 筑的前后左右后退距离、进深面宽之间的比例关系和停车或 卸货区等进行了规定。除上述四方面外, 当今的欧几里得式 区划条例还有针对建筑外观、标识牌和其他美学要素的条款, 这些额外的管制往往是由地方的特别指导委员会进行管理和 执行, 这些特别指导委员会往往是基于特殊的美学要求而设 立, 不属于常规城市区划管理机构, 针对土地和建筑用途的 常规管制不属于其管辖权范畴。

欧几里得式区划条例是由城市民选立法机构任命的顾问 委员会负责管理, 该机构具有准司法性特点。在大多数州, 城市规划委员会中被任命的委员负责为所在社区推荐规划方 案和发展政策, 还负责审查调整区划条例的申请, 并将审查 意见呈报给具有最终决定权的城市立法机构。尽管规划委员 会主要是作为顾问机构, 但也可能会被赋予一定的土地细分 申请的审批权。城市规划委员会的架构和责任最早是在 1926 年由联邦商务部颁布的《标准规划授权法案》中进行了规
定，该法案后来被各州立法机构广泛采用。

《标准区划授权法案》规定设立区划上诉或调整委员会 (ZBA: Zoning Board of Appeals or Adjustment), 受理私有产 权人因客观原因难以满足区划条例中空间尺寸要求而提起的 豁免请求。此外，对于区划条例对每类分区中规定的有条件 或特别土地用途, ZBA 亦有可能具有顾问或决策职能。在 大多数州, 有条件的土地用途往往包括区划条例中列出的可 由社区基于公共需要自由裁量决定的土地用途, 这些土地用 途不能与所在分区的首要土地用途相冲突, 且不得严重影 响社区的特色风貌。由于在管理权限上, ZBA 对市规划委 员会构成制约, 因此其必须满足法律上的正当程序原则, 采 用与法官进行法律判决同样的司法程序和标准。另外, ZBA 的决定也必须满足城市区划条例中规定的管理标准。

\section{1950-1970 年间的土地用途管制}

在 1950 年代末, 欧几里得式区划出现了新的发展趋势。 1957 年, 伊利诺伊州库克县首次在工业区区划条例中创立 了绩效标准（performance standards）。传统工业区的区划条 例仅规定了土地用途、工业类型（例如重工业或轻工业等）、 工厂规模, 以及涉及装卸、停车、仓储和后退等要求, 而绩 效标准还规定了工业企业允许的污染排放标准。要知道, 《联 邦清洁水与空气法案》的颁布和美国国家环保局的成立要一 直等到 1970 年代, 而区划条例中的绩效标准则先于美国国 家层面环境保护立法运动, 是地方政府旨在控制伴随工业化 而来的环境污染的一种努力。这些区划条例规定了针对不同 污染物的排放上限, 包括烟尘、噪音、光污染、震动和气味等, 并规范了针对性的检测方式。例如, 烟尘的检测是使用一张 印有灰度渐变色带的卡片与烟图中排出的烟尘进行对比, 以 确定污染颗粒浓度; 噪音的检测是在距离工业用地最近地块 的边界处用噪音检测仪进行分贝测量。在今天, 即使很多环 境污染问题已经由联邦和州环境保护法律法规进行规制, 但 在大多数工业区区划条例中的绩效标准仍然有效。到了 1980 年代, 绩效标准还被用于规制郊区住宅开发带来的影响 ${ }^{[2]}$ 。

区划条例的另一项创新反映了 20 世纪中叶由美苏太空 竞赛引发的公众对 “科学” 观念和技术进步的崇拜, 并成为 国家主义和主流意识形态的表现。这种时代精神也影响到美 国的城市规划领域。因此, 为了建立一套 “科学的” 区划 体系, 联邦住房管理局在城市更新和新建社区中针对由联邦 资助的集合住宅项目中采用了土地使用强度评价系统（LUI: Land Use Intensity Rating System)。LUI 通过一系列相互联系 的比例规则实现对大型住宅项目的监管, 主要包括容积率、 开放空间和停车位要求等。与欧几里得式区划相比, LUI 的 这些指标更加详细。例如, 将开放空间分为积极开放空间和 
消极开放空间；停车位分为住户停车位和访客停车位等。所 有这些指标被绘制到一张列线图中, 不仅反映出规制标准, 而且在给定用地面积和开发强度的条件下显示出具体的空间 形式 ${ }^{[3]}$ (图 1)。上述做法后因联邦资助的削减和简 ·雅各布 斯的学术批判 (1961) 而终止 ${ }^{[4]}$ 。

关于 LUI 系统需要强调的是, 首先, 容积率中用地面积 的计算并不是基于地块面积, 而是基于周边道路中心线包围的 土地面积: 道路越宽, 项目的有效容积率越高。其次, 土地使 用强度在列线图上直接对应不同的建筑形式, 其中最小值 3.0 对应一层独立式建筑, 最大值 8.0 对应高层建筑。然而, 尽管 LUI 系统运用数值比例进行了 “科学的” 表达, 但它最终与大 型城市更新与新城开发项目一样, 从美国规划实践中消失了。

与此同时, 美国规划实践有了一些新的发展。一是通过 羁束化欧几里得式区划的标准和在 LUI 系统中设定更严格的 比例要求来进一步规范化规划实践; 二是通过在地方区划条 例中引人规划单元开发 (PUD: Planned Unit Development) 以增加管制的弹性。PUD 允许土地所有者突破欧几里得式 区划的标准, 自行进行设计和开发上的创新, 包括组团开发 和混合利用等。土地所有者需要在 PUD 方案评估程序中说 服地方政府突破地方土地利用规划和政策中明确的主观原则 的必要性。然而尽管在该制度下一些标志性项目已建成, 但 PUD 并未（后来也没有）取得成功。因为大部分开发商更 喜欢羁束式区划标准中的确定性, 而非在更复杂和更灵活的 PUD 方案评估中的不确定性和由此带来的项目拖延。

\section{1970一1990 年间的土地用途管制}

随着美国最高法院在 1976 年纽约中央车站对纽约市的 诉讼案中做出支持纽约市地标保护计划的最终判决, 全美很 多社区都设立了地方历史保护委员会, 并引入了历史保护管 制。历史保护管制与区划管制类似, 要求在土地开发前要预 先获得地方政府的审批。但审批依据是其所在州的特别授权 法案, 并由地方特别管理机构（地标或历史保护委员会）来 审批。依据美国历史保护法律, 最主要的决策原则是所涉及 的不动产是否具有建筑或历史价值; 如果有, 其是否该被列 人历史性地标; 如果被列人, 任何有损于该价值的建造和改 造行为将必须获得建设许可。这些决定通常是由一个历史保 护委员会来做出, 该委员会由地方民选官员任命的专家组成。 在大部分社区，历史保护委员会对地方立法机构、州或联邦 历史保护机构行使建议权, 推荐列入地方、州或联邦历史遗 产名录。对于列人名录的建筑, 委员会的审批决定将作为地 方政府颁发开发许可证的前置性条件。

需要强调的是美国历史保护管制在这段时期的发展变 化。首先, 在大部分引人历史保护管制的社区, 历史保护名 录的确定并非由政府单向推动完成, 土地所有者也希望自己 所有的建筑被列入历史保护名录, 因为这将意味着房产价值 的提升或者获得其他的收益。例如, 修缮被列入历史保护名 录的商业地产将享受联邦税收抵免。在一些州征收房地产税 时, 历史建筑还能享受不动产价值的暂时冻结。其次, 并非

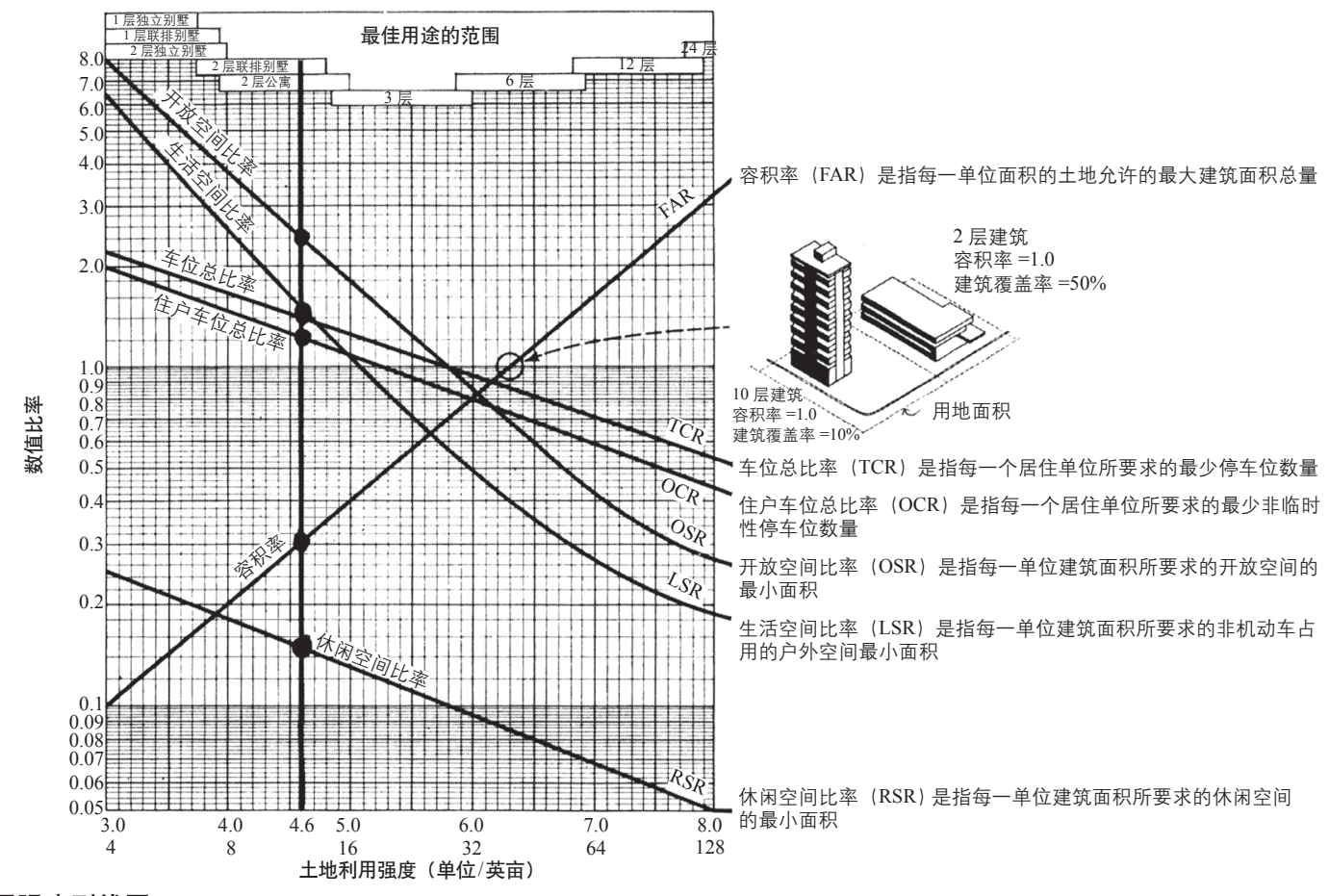

图 1 土地使用强度列线图

资料来源 : 参考文献 $[4]$ 
历史建筑的所有外观部分改造都需要审批, 而仅仅是针对原 本就需要申请建筑许可或其他开发许可的建筑外观部分, 因 为历史保护委员会的审批决定不仅针对土地所有者, 而且还 针对负责进行建筑许可或其他开发许可的地方政府公务员。 所以, 一些可能会影响历史建筑历史价值的改造活动可能摆 脱历史保护委员的监管, 因为这些活动根本不需要申请开发许 可, 例如对建筑立面的重新粉刷或安装一些景观装饰物等。最 后, 所有的地方历史保护条例都包含困境条款, 即当所有者 无法从其所有的历史建筑获得任何经济收益, 或者当仅通过 建筑内部改造无法改变经济不可持续现状时, 允许历史保护 委员会审批那些有损于历史或建筑价值的改造活动。

历史保护名录的范围随着时间不断扩大，除了具有历史 价值的建筑外, 还包括更多种类的构筑物。大部分引入历史 保护管制的社区还划定了历史地区，其中不仅包括具有历史 或建筑价值的构筑物，而且包括本身没有历史或建筑价值的 附属构筑物，但它们是该地区中构成历史环境的不可或缺的 组成要素。不过, 当涉及对附属构筑物的外墙进行更改并有 可能影响其历史性时, 对于这些要素变更的审核要比对于历 史建筑变更的审核简单一些。在一些社区, 对于一些具有重 要历史或建筑价值的建筑, 历史保护委员会除了对建筑外观 改造进行审批外, 还要对室内改造进行审批, 例如, 由著名 建筑师设计的礼堂或建筑大厅。

1970-1990 年这 20 年间, 除了历史保护之外, 美国规 划实践对于美学的关注范围进一步扩大, 很多地方政府都采 用了各种城市设计策略和引人了基于场景和环境的美学管 制, 特别是在一些富人聚集的郊区。这些管制通常包括由公 共建筑审查委员会对新建商业建筑设计的审查, 或者由私人 业主委员会对住宅建筑设计进行干预性更强且更主观武断的 审查。设计审查程序往往由一个居住土地细分区内的所有业 主共同签订的契约限制条款来授权。设计审查条例也许还会 包含区划条例中关于街景和建筑改造的相关要求, 以改善商 业或商务中心区内的步行环境和保持都市特色与建筑质量。

在大城市, 城市设计主要通过两种途径实现: 一是在大 型项目周边划定小范围的特殊区划分区, 在这些区域内规定 特殊的设计要求（例如纽约市时代广场再开发计划）；二是 在敏感地区引人更严格的区划条件, 要求所有大型项目或所 有提出申请的开发项目都必须经由裁量型审批, 从而使得市 政府可以将一些公共设施（例如行道树、带座椅的广场等） 作为审批开发许可的条件 (例如芝加哥的统一规划开发区划 条例) ${ }^{[5]}$ 。此外, 由于联邦和州基础设施资金的削减, 很多 大城市在区划条例中引入激励性内容, 以促进公共设施和其 他城市设计目标的实现。在激励性区划中, 如果开发商在城 市中心区的项目中体现出优秀的城市设计风格, 或为可支付
住房的建设和市政基础设施或交通设施的改善提供资金, 则 可以获得额外的容积率奖励 ${ }^{[6]}$ 。

在 1970 和 1980 年代, 随着基础设施、可支付住房和社 区发展方面联邦资金的大幅削减, 出现了一些土地利用管制 手段的创新, 特别是在城市边缘对新发展项目的管理 ${ }^{[7]}$ 。这 些创新主要包括引人基于基础设施容量的评分系统一一根据 现状和规划的基础设施容量进行评分, 只有超过最低得分才 能颁发开发许可。并且, 有限的州基础设施改善资金将精准投 人到最具开发潜力的地区。作为获得资金的条件, 地方土地利 用规划与区划条例必须遵守州的发展政策。不管采用何种手段, 大部分地方发展控制都是针对新土地开发速度的限制, 以便使 其与基础设施和道路的建设保持一致, 防止因增加州和地方税 收来为新居民的基础设施建设买单而引起选民的不满。

城市增长边界是发展最完善的城市发展管理工具。该边 界的划定是在大城市周边地区, 依据该市历史上的土地开发速 度划定满足 20 30 年新增土地开发存量的范围。在那些因郊区 蔓延导致财政亏损而面临巨大发展压力的州, 城市增长边界因 有利于在区域范围内保护开放空间而越来越受欢迎。在那些没 有面临巨大发展压力的州, 区域发展管理政策主要是以农地保 护政策为主。在农村区划条例中, 一方面大幅提高最小居住用 地面积, 要求每块住宅用地至少有 $16 、 32$ 甚至 $64 \mathrm{hm}^{2}$; 另一 方面对于农业用地则减免房地产税。城市增长边界和农地保护 政策的目标是一致的, 即引导新开发项目集中在现有建设地区 周边和增加城市地区的开发强度, 以尽量缩减为新增居民提供 基础设施的成本, 并在区域范围内保护开放空间。这两种方法 都属于被称为 “精明增长” 的区域发展原则和管制导引 ${ }^{\left[{ }^{[8]}\right.}$ 。

\section{1990一2010 年间的土地用途管制}

1990-2010 年间, 联邦和州持续削减给地方政府的财政 转移支付。例如, 供水和污水处理设施专项拨款已经被州周转 性贷款取代, 该贷款要求地方政府在新设施建成后从带来的收 人中逐年偿还。为了应对公共财政预算的削减, 地方土地利用 管制也进行了诸多创新。其中最重要的创新是对于新增建设项 目征收开发影响费（impact fees）, 用于购买满足新居民需求的 新建基础设施。由于在基础设施建设方面开发影响费对于新居 民秉持 “使用者自付” 的原则, 因此社区没有理由再根据基础 设施容量评分结果进行建设许可的审批, 或者通过其他管制 方法来控制城市增长速度 ${ }^{[9]}$ 。在这 20 年间, 开发影响费逐渐 取代了增长管理成为美国当代规划实践的核心议题, 特别是 在 21 世纪初随着 “房地产泡沫” 而导致新建设量增加的背景 下。2007 年美国的房地产市场崩盘, 由于财政收人进一步减少, 导致地方政府对于开发影响费的依赖仍会持续。

此外, 另外两项重要的创新是在地方土地利用管制中引 
人新都市主义原则和将公交导向发展 (TOD) 作为商业开 发与再开发的重要模式 ${ }^{[10]}$ 。新都市主义与 TOD 均反映出后 现代主义设计原则, 在新规划项目中体现出对源自传统开发 形式的尊重。新都市主义提倡密集紧凑、步行导向和混合利 用式的开发模式, 以保护开放空间和改善城市生活质量 ; 而 TOD 则利用公共交通的优势鼓励商业开发围绕交通枢纽, 在 设计手法上源自 19 世纪城市社区的风格, 在公交车站周边进 行高强度零售业开发。然而与 1970 年代的 PUD 类似, 业界 对于新都市主义和 TOD 理念的追捧并没有被房地产市场广 泛接受。与依据欧几里得式区划原则进行的传统居住和商业 开发相比, 按照新都市主义或 TOD 模式进行开发的项目数 量很少。背后的原因也很类似, 即 : 尽管在很多地方区划条 例中都明确表示了鼓励这些后现代主义发展模式, 但欧几里 得式区划因其要求清晰明确而具有更大的确定性, 因此减少 了在与地方政府关于设计风格、基础设施和公共设施等方面 进行反复沟通协商的成本, 开发商可以较快地获得开发申请。

最后, 形态条例 (form-based codes) 也是在最近的 20 年间出现的。这种条例通过适用于整个社区的统一性设计导 则来对具体项目的设计过程进行管理 ${ }^{[11]}$ 。与 1970 和 1980 年 代出现的城市设计审查一样, 形态条例的主要目的也是通过 设计标准来管理建筑体量与设计风格, 以保证城市中再开发 项目与既有社区风格一致。在 20 世纪末和 21 世纪初的房地 产建设高潮中, 高地价和低利息促使开发商在绅士化社区的 再开发项目中尽可能建造大体量建筑以实现收益最大化, 但 破坏了街道景观, 因此形态条例显得尤为重要。由于 2007 年银行金融体系崩溃, 美国规划界最近很少听到关于形态条 例的讨论, 但相信随着房地产业在新一轮的经济循环中再一 次步入高潮, 形态条例将会重新受到规划界的关注。

\section{0 年以后土地用途管制发展的趋势}

与 1960 年代在欧几里得式区划条例中针对工业用地的绩 效标准类似, 近年来规划实践界再一次开始关注改善环境质量 的问题。例如, 在区域和地方范围内, 陆地和水系的生态系统 保护在一些土地利用规划中开始作为规划目标。但由于缺乏关 于栖息地面积和野生动物廊道连接性等方面的科学明确的监 管标准, 导致在实践上依然大大落后于政策 ${ }^{[12]}$ 。区域生态系 统规划与绘图的发展也提高了作为土地用途管制法定内容的 生态系统管理的可视化 (例如, 芝加哥市自然环境与野生动物 保护规划中的生态系统地图)。随着未来城市建成区不断向城 市周边的环境敏感区蔓延, 对环境保护规划的关注将持续升温。

另一个正在出现的趋势是可持续发展, 特别是当地方发 展规划与减缓全球气候变化发生联系时 ${ }^{[13]}$ 。越来越多的美国 社区开始将可持续发展作为规划目标, 并且发展出新的土地
用途管制工具, 要求土地所有者遵守旨在保护环境的 “最佳 管理实践” (BMPs: Best Management Practices), 特别是在城 市雨水管理领域。水质规划在美国已有很长的历史, 而现在 的一些做法成为新的土地用途管制策略。历史上, 新建集中 式的雨水收集设施和污水处理设施被认为是解决新建设带来 的水污染问题的最重要的技术手段。在整个 20 世纪, 开发 商都被要求在土地细分地块中安装污水管网和雨水设施, 以 作为获得开发许可的必要条件。今天, 技术手段已经开始转 向利用场地内的生态系统和 “绿色基础设施” 来处理城市雨 水。这些分散式的解决手段并不依赖于有限的公共投资, 而 是由开发商或土地所有者在其所有的土地内自行解决。

这些都将要求发展出针对绿色基础设施和生态系统管理的 适合的监管标准, 以及在开发项目获得审批后保证建设与运营 能够按照该标准实行的机制。例如，一些社区正在考虑设置雨 水管理费以用于日常监察。同样从能源保护的角度, 在可持续 发展和减缓气候变化的地方规划中, 发展出减少碳排放的监管 标准和机制也十分迫切。关于未来新的环境保护政策, 最有趣 的是我们也许会回到土地用途管制的逻辑起点, 采用让私人更 多承担可持续发展和能源保护责任的去中心化解决方式, 而非 用公共政策、行动和监管的中心化解决方式。具有讽刺意味的是, 美国也许正趋于采纳 19 世纪而非 21 世纪的管制哲学。 UP

\section{参考文献}

[1] Comey A C. Maximum Building Height Regulation[J]. Landscape Architecture, 1912, 3: 19-24.

[2] Kendig L. Performance Zoning[R]. Chicago: American Planning Association, 1980.

[3] Hanke B. Planned Unit Development and Land Use Intensity[J]. University of Pennsylvania Law Review, 1965, 114(1): 15-46.

[4] Jacobs J. The Death and Life of Great American Cities[M]. New York: Vintage Books, 1961.

[5] Barnett J. Redesigning Cities: Principles, Practice, Implementation[R]. Chicago: American Planning Association, 2003.

[6] Whyte W. City: Rediscovering the Center[M]. New York: Doubleday, 1989.

[7] Kelly E. Managing Community Growth [M]. 2nd ed. New York: Praeger, 2003.

[8] Duany A, Speck J, Lydon M. The Smart Growth Manual[M]. New York: McGraw-Hill, 2009.

[9] Altschuler A, Gomez-Ibanez J, Howett A. Regulation for Revenue: The Political Economy of Land Use Exactions[M]. Washington DC: Brookings Institution Press, 1993.

[10] Katz P. The New Urbanism: Towards an Architecture of Community[M] New York: McGraw-Hill, 1993.

[11] Parolek D, Parolek K, Crawford P. Form Based Codes: A Guide for Planners, Urban Designers, Municipalities and Developers[M]. New York: Wiley, 2008.

[12] ELI. Conservation Thresholds for Land Use Planners[R]. Washington DC: Environmental Law Institute, 2003.

[13] Beatley T. Biophilic Cities: Integrating Nature into Urban Design and Planning[M]. Washington DC: Island Press, 2010. 